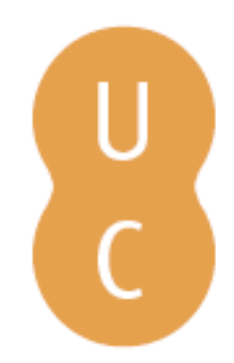

\title{
nombalina
}

\section{Planeamento e gestão de frentes de água: a frente ribeirinha norte de Almada, novos usos, novos tempos}

\author{
Autor(es): $\quad$ Almeida, Diana \\ Publicado por: Imprensa da Universidade de Coimbra \\ URL \\ persistente: URI:http://hdl.handle.net/10316.2/30813 \\ DOI: $\quad$ DOI:http://dx.doi.org/10.14195/978-989-26-0244-8_38 \\ Accessed : $\quad$ 26-Apr-2023 10:50:12
}

A navegação consulta e descarregamento dos títulos inseridos nas Bibliotecas Digitais UC Digitalis, UC Pombalina e UC Impactum, pressupõem a aceitação plena e sem reservas dos Termos e Condições de Uso destas Bibliotecas Digitais, disponíveis em https://digitalis.uc.pt/pt-pt/termos.

Conforme exposto nos referidos Termos e Condições de Uso, o descarregamento de títulos de acesso restrito requer uma licença válida de autorização devendo o utilizador aceder ao(s) documento(s) a partir de um endereço de IP da instituição detentora da supramencionada licença.

Ao utilizador é apenas permitido o descarregamento para uso pessoal, pelo que o emprego do(s) título(s) descarregado(s) para outro fim, designadamente comercial, carece de autorização do respetivo autor ou editor da obra.

Na medida em que todas as obras da UC Digitalis se encontram protegidas pelo Código do Direito de Autor e Direitos Conexos e demais legislação aplicável, toda a cópia, parcial ou total, deste documento, nos casos em que é legalmente admitida, deverá conter ou fazer-se acompanhar por este aviso.

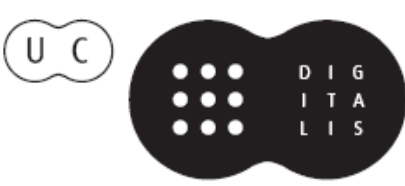




\section{TRUNFOS DE UMA}

\section{EOGRAFIA ACIVA}

\section{DESENVOLVIMENTO LOCAL,}

AMBIENTE,

ORDENAMENTO

E TECNOLOGIA

Norberto Santos

Lúcio Cunha

COORDENAÇÃO 
Diana Almeida

Centro de Estudos Geográficos, Instituto de Geografia e Ordenamento do Território (IGOT), Universidade de Lisboa

\author{
PLANEAMENTO E GESTÃO DE FRENTES DE ÁGUA \\ - A FRENTE RIBEIRINHA NORTE DE ALMADA, NOVOS USOS, NOVOS TEMPOS.
}

\title{
1. INTRODUÇÃO
}

As frentes de água são, desde do início dos estabelecimentos humanos, áreas preferencialmente escolhidas para o surgimento das cidades. A proximidade da água, como afirmam Hoyle e Pinder (1992), favoreceu as acessibilidades e os transportes marítimo-fluviais, as trocas comerciais. Para além das funçóes referidas, o elemento água permite, entre outras, funçôes recreativas, lúdicas e desportivas.

Neste contexto, o planeamento associado às frentes de água deve ocupar um papel central na estratégia urbana e nas políticas de cidade. Os actores institucionais e locais devem ser chamados ao processo de planeamento, através da participaçáo pública, pois estes, no seu conjunto, aqueles que vivem o espaço e são capazes de o transformar de acordo com a sua identidade colectiva. Castells (1996:26) salienta papel decisivo que a identidade desempenha no contexto dos actores:

«[...] por identidade, entendo o processo pelo qual um actor social se reconhece a si próprio e constrói significado, sobretudo, através de um dado atributo cultural ou conjunto de atributos culturais determinados, a ponto de excluir uma referência mais ampla a outras estruturas sociais.»

Desta forma, a identidade do actor social é essencial para a construção de um lugar, pois transporta o cunho cultural e pessoal de cada actor, diferenciando a sua posiçáo e/ou intervenção, hierarquizando sucessivamente valores sociais e espaciais, fazendo-os reflectir sobre determinado lugar.

$\mathrm{O}$ artigo tem por base uma dissertação de mestrado, em que o objectivo principal reside na análise da evolução das frentes de água urbanas como espaço público; no estudo e compreensão dos mecanismos de planeamento aplicados às frentes de água e na percepção do papel dos actores na transformação do espaço.

Encontra-se organizado em cinco pontos. $\mathrm{Na}$ introdução apresentam-se os objectivos e a estrutura do artigo, seguindo-se a identificação da metodologia utilizada. O ponto dos Resultados e Discussão centra-se na análise e tratamento das entrevistas realizadas ao grupo de indivíduos-chave, combinado com os resultados do levantamento funcional. As conclusôes são o último capítulo, onde são apresentadas algumas propostas. 


\section{Metodologia e Caso de Estudo}

A frente ribeirinha Norte de Almada localiza-se na margem Sul do Tejo, no distrito de Setúbal, concelho de Almada, e abrange as freguesias de Almada e Cacilhas. A área de estudo tem uma extensão de cerca de 1.600 metros e é limitada a Sul pela Arriba fóssil que acompanha toda esta área, e a Norte pelo Rio Tejo.

Entre os séculos XVIII e XX, teve funçôes habitacionais, fabris, recreativas e culturais (Flores, 1987). Porém, nos dias de hoje, este território está em avançado estado de degradação. Foram identificadas quatro áreas na frente ribeirinha norte de Almada, o Ginjal, a Boca do Vento, o Olho-de-Boi e a Quinta da Arealva, em que a distinçáo das mesmas está relacionada com a marca industrial reflectida na arquitectura do edificado e nas funçóes que permanecem. Estas características multiplicam-se nos edifícios ricos em arqueologia industrial, alternados com um passeio ribeirinho onde prevalecem elementos portuários relevantes. Simultaneamente, a frente de água tem vindo a ser palco de fenómenos, de pequena dimensão, de intervenção urbana na óptica da recuperação, reintrodução, manutenção e inovação.

A pergunta de partida assenta no papel dos actores territoriais na reconversão da Frente Ribeirinha Norte de Almada e nos impactos na utilizaçáo do espaço público. Interessa compreender quem são os actores que actualmente exercem funçóes naquela frente de água (sejam profissionais, de lazer ou habitacionais); que transformaçôes têm acontecido no frente ribeirinha Norte de Almada; em que medida são os novos actores territoriais os responsáveis por essa mudança funcional; quais os impactos na utilização do espaço público; e em que medida as actividades actuais privilegiam uma apropriaçáo nocturna do espaço.

Colocou-se a hipótese de investigação - as actividades que têm vindo a ser desenvolvidas na Frente Ribeirinha Norte de Almada resultam da intervenção dos actores territoriais, que por sua vez produzem alteraçóes no uso do espaço público à noite. Pretende-se identificar as novas funçôes da frente ribeirinha, em que medida essa refuncionalização advém da interferência dos actores, e na prática perceber o que se altera no uso do espaço público, nomeadamente, durante o período nocturno.

O levantamento funcional foi um dos instrumentos de análise utilizados. Proporcionou o conhecimento das funçôes/actividades que actualmente estão em prática, das características do edificado e do passeio ribeirinho. As categorias analisadas têm por base Alves (2003), acerca dos elementos do espaço público, vias de acesso, constrangimentos e qualidade. Os inputs foram os seguintes: Edificado (estado do edificado; número de pisos; cadastro, arqueologia industrial; elementos portuários); Funçóes (levantamento funcional); Acessibilidades (passeio ribeirinho - tipologia da pavimentação; protecção da frente de água; acessos terrestres - obstrução da via; estacionamento); Qualidade (iluminação; espécies vegetais; mobiliário urbano; ruído).

Para aferir a percepção dos actores acerca do território em análise foi utilizado o método de entrevistas, semi-dirigidas, que se caracteriza pela existência prévia de um guião de entrevista, ao qual o entrevistado deve responder. A preferência pelas entrevistas em detrimento dos inquéritos, deveu-se à riqueza da interacção proporcionada e pelos elementos adicionais que se poderia retirar da entrevista, fulcrais para o processo de reflexão. Os actores entrevistados foram seleccionados pela sua relação directa com a área de estudo, subdividindo-se em actores institucionais (ICNB, APL, Câmara Municipal de Almada) e actores territoriais (moradores e profissionais). A análise das entrevistas baseia-se numa tabela em que se cruzam 
as respostas dos entrevistados, tentando formar uma matriz sistematizada: utilizaram-se dois métodos de leitura - a análise categorial, que consiste em averiguar a frequência com que determinados temas ou características são mencionados pelo entrevistado, agrupando-as posteriormente em classes expressivas; e a análise da avaliação, que reflecte sobre os juízos de valor (positivos ou negativos) enunciados pelo locutor e qual a sua frequência/intensidade. Foram analisados os seguintes domínios: vantagens e potencialidades; problemas, constrangimentos e entraves; atractividade, representatividade e relação entre os actores; espaço público diurno e nocturno; acessibilidades; reconversão da frente de água; actividade: iniciação e horário de permanência; perspectivas futuras.

\section{RESUlTAdOS E DisCUSSÃO}

As frentes de água evoluíram e foram-se transformando à medida das tendências da cidade. Umas devido ao desmantelamento do antigo porto, que deixou grandes áreas livres na linha de água e no centro da cidade, outras intervençóes surgiram baseadas em eventos de carácter efémero, que se acabaram por eternizar, outras ainda vão-se construindo à medida de que a cidade avança em direcçáo à frente de água (Norcliffe et. al, 1996; Sousa, 2003; Rafferty, 2004). É de reter o seguinte: a) o mix funcional é um modelo a seguir, quando o objectivo da intervenção é dinamizar a frente de água em todas as suas dimensóes, inserindoa no contexto urbano; b) a participação pública é fundamental não só para a construção das frentes de água, como também para todo o processo de planeamento - o envolvimento das comunidades nas fases de proposta de projecto, no processo de decisão e durante a gestáo, são essenciais para o desenvolvimento de uma cidade e para a construção urbana; c) o processo contínuo - os planos para as frentes de água devem reunir as seguintes características: serem projectos a longo prazo, abertos e flexíveis (WaterfrontExpo Guiding Principles, 2007). A construçáo da frente de água urbana implica a constante actualizaçáo das necessidades das pessoas, incluindo a capacidade de adaptar as funçóes projectadas, às mudanças sociais e económicas. Para além dos promotores, construtores e consultores, o conjunto dos actores que usufruem do espaço, que o conhecem e actuam sobre ele (sejam moradores ou comerciantes) constituem o grupo para quem se destina o espaço, desempenham um papel fulcral nas fases de decisão (Alves, 2003, Kärrholm, 2007). Os actores territoriais não substituem o planeamento, mas contribuem para a formação da massa crítica. O seu papel adquire particular relevância na sensibilização e na mobilização, por parte dos decisores, em avançarem com um plano, deslindando o melhor caminho a ser seguido para aquele território.

A ligação com o mar ou com o rio permite o desenvolvimento de um conjunto de actividades associadas ao recreio e ao turismo que tornam a frente de água indissociável da cidade. Raferty (2004) reforça a capacidade atractiva das frentes de água, aliadas à divulgação da imagem da cidade, contribuindo igualmente para a sua construção identitária. Neste sentido, os eventos criativos, a existência periódica de espectáculos, capazes de atraiam residentes e visitantes, vai reflectir-se no consumo dos bens e serviços igualmente disponíveis no conjunto da frente de água (Urban Land Institute, 2004), gerando todo um sistema de mais-valia, sobretudo para os actores locais. 
Figura 1 - Carta dos Elementos Portuários

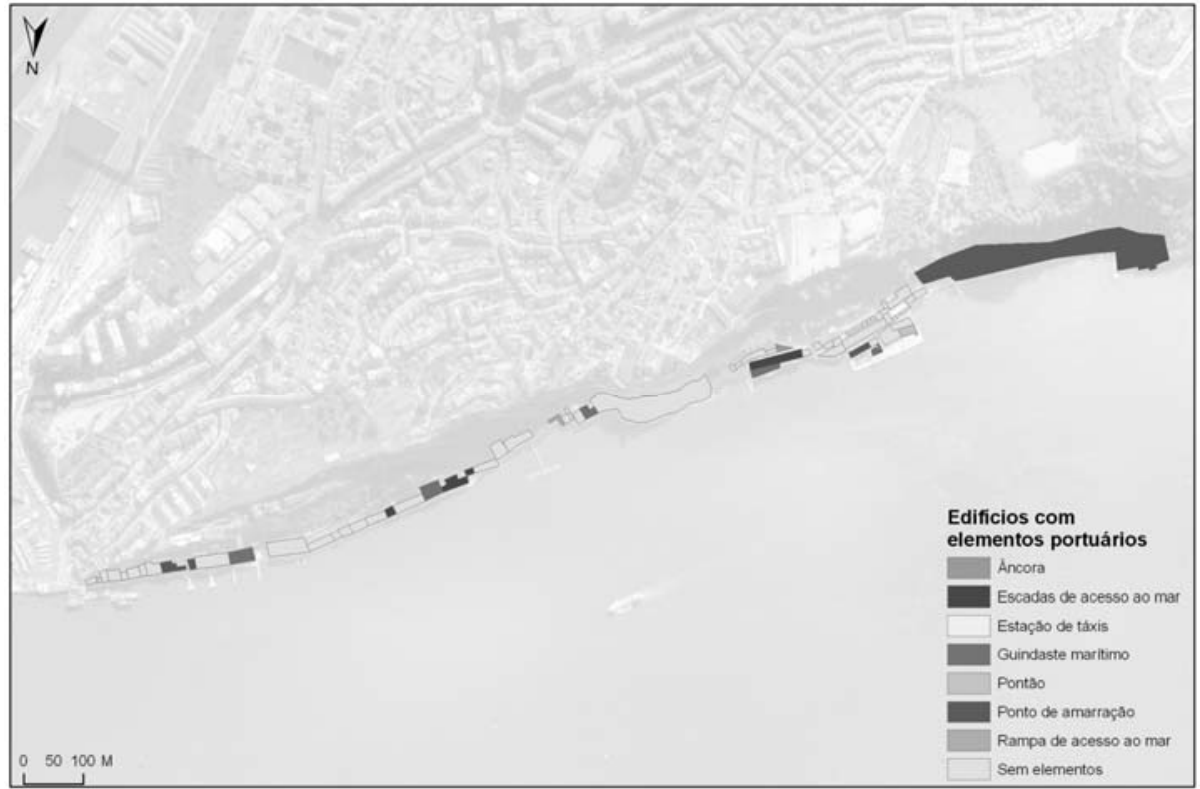

O levantamento funcional permitiu conhecer cinco realidades que coexistem em simultâneo na frente de água, e nas quais as dinâmicas económicas e de utilizaçáo do território são distintas e bem diferenciadas espacialmente.

Figura 2 - Carta do Levantamento Funcional

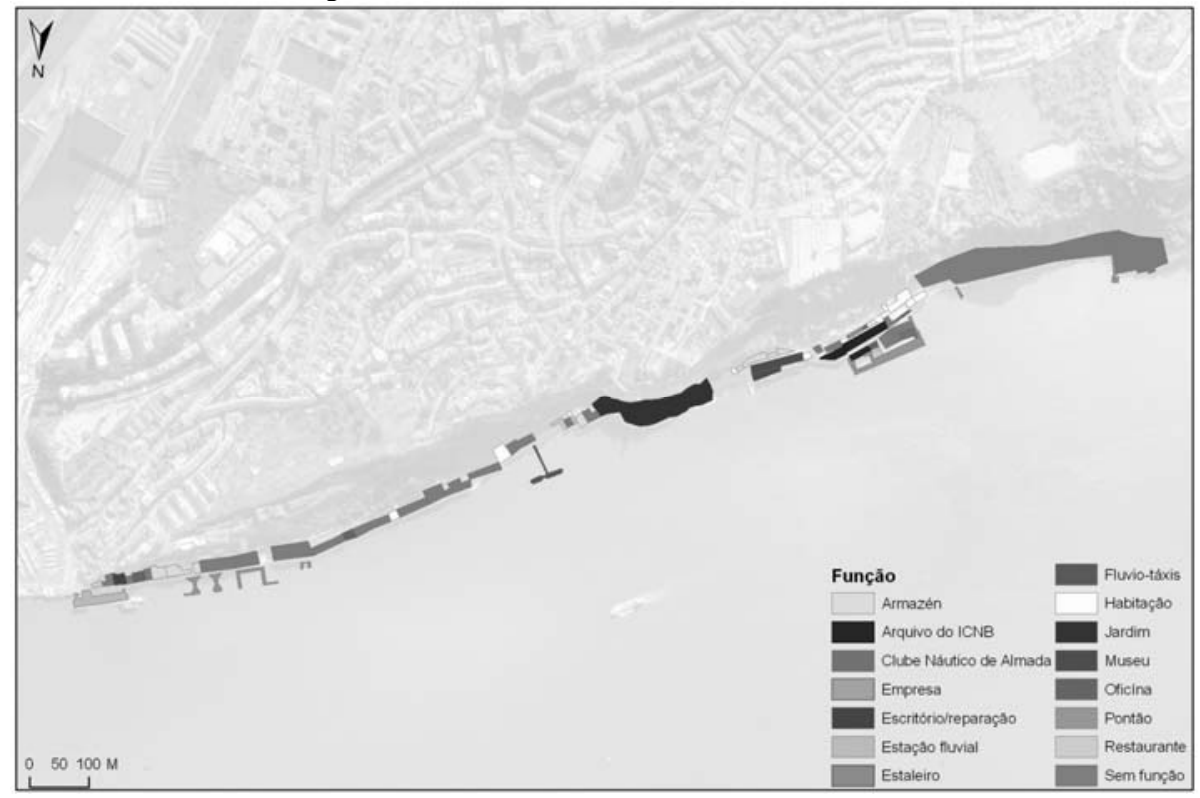


A diversidade patrimonial em termos de arquitectura industrial e a riqueza do legado dos elementos portuários que permanecem no edificado de toda a frente de água, constituem fortes potencialidades atractivas à frente ribeirinha. $\mathrm{O}$ processo de intervenção ribeirinha contaria com a sua conservaçáo e requalificação, mantendo simultaneamente a identidade cultural (dos actores) e a imagem associada à frente de água, bem como teria capacidades para aumentar a utilização do espaço público.

A área mais próxima de Cacilhas apresenta uma vivacidade associada às actividades económicas derivadas do transporte fluvial, e ainda a existência de oficinas e armazéns. Nesta área os quantitativos de luz são satisfatórios para a circulação nocturna, embora não seja uma prática recorrente; até à praia das Lavadeiras, onde se situam os restaurantes, o cais do Ginjal possui um vasto conjunto de edifícios abandonados e degradados, interrompidos por dois nichos de habitação; a partir da curva do antigo clube náutico de Almada, o espaço transfigura-se, quer de dia, quer de noite. Os cuidados com o edificado e com a qualidade do espaço público são notáveis; as instalaçóes da ex Companhia Portuguesa de Pescas funcionam quase que como uma ilha à parte do cordão ribeirinho.

Deve-se sobretudo a quatro factores: à unidade de conjunto proporcionada pela herança das anteriores actividades, à existência de um considerável número de residentes que cuidam do espaço, à diversidade das actividades económicas e fundamentalmente, à oferta de acessos terrestres diversificados, como a estrada que serve o transporte motorizado, que pode ser percorrida pedonalmente, e o elevador.

A habitaçáo deve ser o ponto de partida para a existência de usos mistos, como sendo a habitação, escritórios, restauração, cultura, animação. No caso da frente ribeirinha norte de Almada, esta deve ser dirigida para os jovens, como ponto de partida para a dinamizaçáo do espaço público, nocturno e diurno: apostar na organizaçáo de evento que aconteçam à noite e que permitiam a valorização das estruturas portuárias e dos vários elementos do património arquitectónico, que caracterizam de forma singular esta paisagem ribeirinha e que funcionem como atractivo.

Os transportes e as acessibilidades desempenham um papel fundamental, não só para a divulgação e promoção da frente ribeirinha como espaço público de lazer, mas como espaço para trabalhar e para residir.

É possível afirmar que os actores da frente ribeirinha Norte de Almada têm um papel preponderante na construção do espaço público, tanto diurno, como nocturno, sendo também eles, elementos-chave no processo de reconversão da frente de água. Os actores territoriais entrevistados coincidem com representantes, ou trabalhadores das actividades económicas que se encontram ao longo da frente de água.

Analisando a hipótese colocada, esta só se verifica no espaço-tempo do dia, onde a grande maioria dos actores, exerce a sua actividade económica e estabelece uma relação mais directa com o território e constrói relaçóes com os outros actores, sejam pessoais ou profissionais. Os restaurantes constituem o grupo de actores, onde a presença no espaço e no tempo é mais alargada, penetrando pela noite, e portanto, adquiriram uma percepção da vivência nocturna que difere dos outros actores. No entanto, a sua existência não é inovadora, um deles localiza-se no lugar de uma antiga taberna, ainda do tempo dos Armadores da Pesca do Bacalhau (1930, segundo Sr. João, morador do Ginjal e ex-trabalhador da Companhia de Pescas Portuguesa), a forma como se apresenta e explora as potencialidades do local é que é nova. 
Figura 3 - Carta do Estado do Edificado

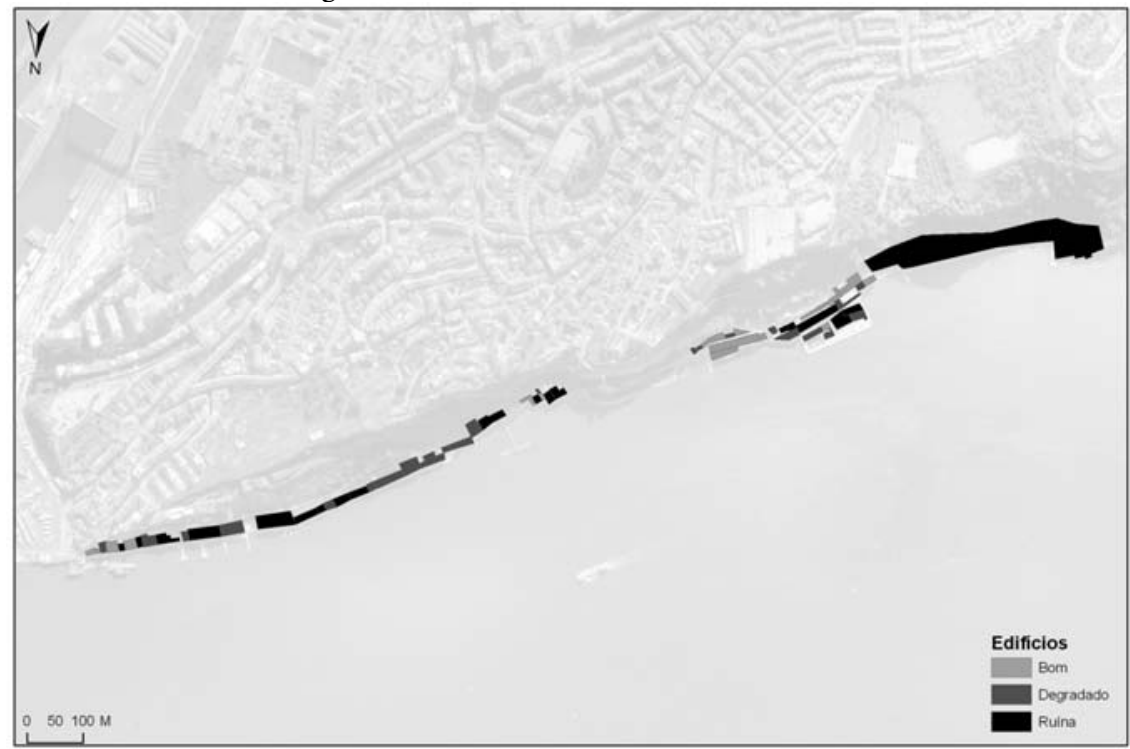

Figura 4 - Carta dos Acessos Terrestres

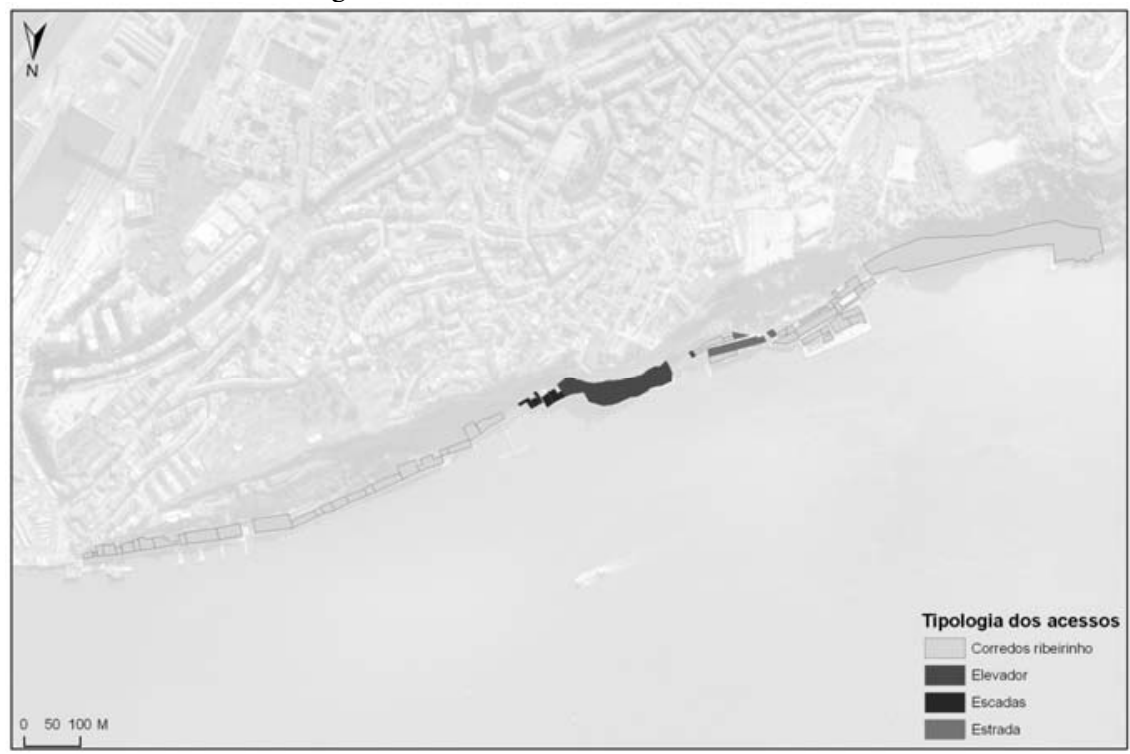

O processo de gestão, no entender de Alves (2003:241), é encarado como o

[...] processo de controlo do uso do espaço resultante e de manutenção e aferição da sua forma à mudança das necessidades a satisfazer, cabe-lhe um papel de cariz prospectivo [...], cíclico e também criativo [...]». 
Neste processo é necessário satisfazer as necessidades dos utilizadores do espaço, conhecer o seu perfil e perceber o que procuram/ esperam desse mesmo espaço. A gestáo não pode apenas estar associada ao garante da segurança, higiene ou da iluminação de um espaço público. No caso das frentes de água, a sua multiplicidade de usos e funçóes, multiplica os cuidados na óptica da manutenção e constante recriação do lugar, estimulando nas pessoas a identificação e a pertença.

A capacitação dos actores territoriais de um efectivo envolvimento no processo de planeamento, através da participação pública afigura-se como processo inerente da vida e das intervençóes na frente ribeirinha Norte de Almada. Incorporar os actores territoriais no modelo de gestáo futuro, de modo a que as intençóes, os desejos, as vontades e ambiçóes protagonizados pelos indivíduos que utilizam e fruem o espaço, seja através de actividades económicas, seja na perspectiva pessoal como cidadãos e conhecedores da frente de água, funcionem como elementos chave à perenidade e renovação do projecto de intervençáo na frente ribeirinha Norte de Almada.

\section{CONCLUSÓES}

Vários são os aspectos marcantes da frente ribeirinha Norte de Almada, que a diferenciam positivamente e que abrem simultaneamente portas para projectos de intervenção, no sentido da requalificação e reconversão. A diversidade patrimonial em termos de arquitectura industrial e a riqueza do legado dos elementos portuários que permanecem, quer no edificado, quer no próprio passeio ribeirinho, constituem fortes potencialidades, atractivas para residir, para trabalhar e para os lazeres. Estes elementos foram diversas vezes mencionados pelos actores, como elementos-chave para a sua identificação pessoal com aquele território. A identidade cultural (dos actores) e a imagem que os mesmos têm da frente de água, deriva de uma simbiose entre as reminiscências do período fabril e da indústria naval que tanto marcaram este território, e um desejo de modernização, no sentido de contrariar a degradação urbana.

Assim, a habitação deve ser o ponto de partida para a existência de usos mistos, como escritórios, restauração, cultura, animação. No caso da frente ribeirinha norte de Almada, esta deve ser dirigida para uma camada mais jovem, com disponibilidade e flexibilidade de horários, usufruindo o espaço público também à noite. A função residencial, aliada com um conjunto de eventos, comércio, equipamentos culturais, desportivos entre outros, possibilita um ganho recíproco para os actores locais, e para a cidade de Almada, ao mesmo tempo que a Área Metropolitana de Lisboa ganha mais uma área de cultura e lazer, de visitas turísticas e de investimentos. Como já foi mencionado na identificação dos vários tipos de transformação nas frentes de água, os eventos de carácter efémero e ritualizado, constituem um forte dinamizador do espaço público. Propóem-se uma aposta na organização de eventos que aconteçam à noite e que permitiam a valorização das estruturas portuárias e dos vários elementos do património arquitectónico, que caracterizam de forma singular esta paisagem ribeirinha e que funcionem como atractivo.

Porém, o processo de planeamento deve incluir uma fase de gestão dos ganhos e das percas. O processo de gestão, no entender de Alves (2003:241), é encarado como o: 
[...] processo de controlo do uso do espaço resultante e de manutenção e aferição da sua forma à mudança das necessidades a satisfazer, cabe-lhe um papel de cariz prospectivo [...], cíclico e também criativo [...]».

Neste processo é necessário satisfazer as necessidades dos utilizadores do espaço, conhecer o seu perfil e perceber o que procuram/ esperam desse mesmo espaço. A gestáo não pode apenas estar associada ao garante da segurança, higiene ou da iluminação de um espaço público.

No caso das frentes de água, a diversidade de usos e funçôes multiplica os cuidados na óptica da manutenção e constante recriação do lugar, estimulando nas pessoas a identificação e a pertença. Assim, os actores territoriais, devem ser o início e o fim de um ciclo de consciencialização da frente de água como um espaço público de uso colectivo. Desta forma, a capacitaçáo dos actores territoriais de um efectivo envolvimento no processo de planeamento, através da participação pública, afigura-se como processo inerente da vida e das intervençóes na frente ribeirinha Norte de Almada. Incorporar os actores territoriais no modelo de gestão futuro, de modo a que as intençóes, os desejos, as vontades e ambiçóes protagonizados pelos indivíduos que utilizam e fruem o espaço, seja através de actividades económicas, seja na perspectiva pessoal como cidadáos e conhecedores da frente de água, funcionem como elementos chave à perenidade e renovação do projecto de intervenção na frente ribeirinha Norte de Almada.

\section{REFERÊNCIAS BIBLIOGRÁFICAS}

Alves, F. B. 2003, Avaliação da Qualidade do Espaço Público Urbano. Proposta Metodológica, Fundação Calouste Gulbenkian, Fundação Para a Ciência e Tecnologia, MCES.

Alves, T. 2007, "A noite, a cidade e a geografia das actividades económicas», in Geophilia. O sentir e os sentidos da Geografia. Homenagem a Jorge Gaspar, ed. Centro de Estudos Geográficos, Lisboa, pp.498-500.

Câmara Municipal de Almada 1997, Plano Director Municipal de Almada,

Castells, M. 1996, The Rise of the Network Society. Blackwell. Oxford.

Flores, A. M. 1987 - Almada antiga e moderna, Roteiro Iconográfico, Vol. II, Junta de Freguesia de Cacilhas, Almada.

Gonçalves J. 2006, Os Espaços Públicos na Reconfiguração Física e Social da Cidade, Colecção Tese, Universidade Lusíada Editora.

Hindess B. 1990, «Analyzing Actors' Choices», International Political Science Review, Vol. 11, n.1, pp.87

Hoyle \& Pinder 1992, Cities and the Sea: change and development in contemporary Europe, European Ports in Transition, University of Southampton, ed. Belhaven Press, London, pp.1-19.

Kärrhorlm M. 2007, "The Materiality of Territorial Production: a Conceptual Discussion of Territoriality, Materiality, and the everyday life of Public Space», Space and Culture Vol.10, n.4, Sage Publications, pp.437-453

Norcliffe G., Bassett, K., Hoare, T. 1996, "The emergence of postmodernism on the urban waterfront Geographical perspectives on changing relationships», Journal of Transport Geography, Vol.4, n.2, Elsevier Science, pp.123-134.

Rafferty \& Holst 2004 "An Introduction to Urban Waterfront Development», in Remaking the Urban Waterfronts, ed. Urban Land Institute.

Sassen S. 2004, "Local Actors in Global Politics», Current Sociology, Vol. 52, n.4, pp.649-670 SAGE Publications

Sousa J.F. 2003, «Enclaves territoriais no ordenamento das orlas costeiras - o caso dos espaços portuários», in Portos, Transportes Maritimos e Território, Lisboa.

WaterfrontExpo, 2007, WaterfrontExpo Guiding Principles, disponível em: http://www.waterfrontexpo.com/ /expo/2007lisbon/principles.shtml 